Research paper

\title{
Lymphocyte proliferation and apoptosis of lymphocyte subpopulations in bovine leukemia virus-infected dairy cows with high and low proviral load
}

\author{
María Victoria Nieto Farias ${ }^{\mathrm{a}}$, Fernando Nogueira Souza ${ }^{\mathrm{b}}$, Pamela Anahí Lendez ${ }^{\mathrm{a}}$, \\ Lucía Martínez-Cuesta ${ }^{\mathrm{a}}$, Kamila Reis Santos ${ }^{\mathrm{b}}$, Alice Maria Melville Paiva Della Libera ${ }^{\mathrm{b}}$, \\ María Carolina Ceriani ${ }^{a}$, Guillermina Laura Dolcini ${ }^{a, *}$ \\ ${ }^{a}$ Laboratorio de Virología, Centro de Investigación Veterinaria de Tandil (CIVETAN, CONICET-UNCPBA-CICPBA), Facultad de Cs. Veterinarias, UNCPBA, Paraje Arroyo \\ Seco s/n, 7000, Tandil, Argentina \\ ${ }^{\mathrm{b}}$ Veterinary Clinical Immunology Research Group, Departamento de Clínica Médica, Faculdade de Medicina Veterinaria e Zootecnia, Universidade de São Paulo, Av. Prof. \\ Dr. Orlando Marques de Paiva 87, Cidade Universitária, São Paulo, 05508-270, Brazil
}

\section{A R T I C L E IN F O}

\section{Keywords:}

Bovine leukemia virus

Proviral load

B-lymphocytes

T-lymphocytes

Proliferation

Apoptosis

\begin{abstract}
A B S T R A C T
Bovine leukemia virus (BLV) is one of the most important virus in dairy cattle. The infection behavior follows what we call the iceberg phenomenon: $60 \%$ of infected animals do not show clinical signs; $30 \%$ develop persistent lymphocytosis (PL); and the remaining 10\%, die due to lymphosarcoma. BLV transmission depends on infected cell exchange and thus, proviral load is determinant. Understanding the mechanisms by which cattle governs the control of viral dissemination will be desirable for designing effective therapeutic or preventive strategies for BLV. The development of high proviral load (HPL) or low proviral load (LPL) might be associated to genetic factors and humoral immune responses, however cellular responses are not fully described. It is known that BLV affects cellular homeostasis: proliferation and apoptosis. It is also known that the BLV tropism is directed towards B lymphocytes, and that lymphocytotic animals have elevated amounts of these cells. Usually, when an animal is infected by BLV, the B markers that increase are CD21, CD5 and CD11b. This increase could be related to the modulation of apoptosis in these cells. This is the first work in which animals infected with BLV are classified according to their proviral load and the subpopulations of B and T lymphocytes are evaluated in terms of their percentage in peripheral blood and its stage of apoptosis and viability. PBMCs from HPL animals proliferated more than LPL and non-infected animals. CD11b ${ }^{+} / \mathrm{CD} 5^{+}$lymphocytes in LPL animals presented greater early and late apoptosis than HPL animals and cells of HPL animals had increased viability than LPL animals. Our results confirm that BLV alters the mechanism of apoptosis and proliferation of infected cells.
\end{abstract}

\section{Introduction}

Bovine leukemia virus (BLV) is a deltaretrovirus, the most widespread pathogen in dairy cattle. It is the etiological agent of enzootic bovine leukemia (EBL), a disease characterized by three different presentations: asymptomatic or aleukemic (AL), persistent lymphocytosis (PL), and leukemia or lymphoma (Bartlett et al., 2013). Approximately $30 \%$ of infected animals will develop PL, while $0.1-10 \%$ of infected animals will develop either leukemia or lymphoma (Kabeya et al., 2001). PL stage is characterized by a polyclonal B-cell expansion that occurs almost exclusively within the $\mathrm{CD}^{+} \mathrm{B}$-cell subset, which are in turn the primary target for BLV proviral integration. This accumulation of B-lymphocytes in blood and lymphoid tissue potentially cause leukemia/lymphoma, especially in PL cattle (Gillet et al., 2007; Florins et al., 2007).

BLV transmission occurs by exchange of cells harboring the virus, so the number of infected cells in the animal is crucial (Hopkins and DiGiacomo, 1997). Even though PL cattle are considered the most risky for transmission, asymptomatic animals may also play a role depending on their proviral load (Juliarena et al., 2007). In fact, approximately $60 \%$ of the AL animals present low proviral load (LPL), while the remaining $40 \%$ will be AL animals with high proviral load (HPL) (Juliarena et al., 2007). The ability to control viral spread in infected animals could be associated in part to host genetic factors, such as polymorphisms in the bovine leukocyte antigen (BoLA) gene (Juliarena et al., 2008; Polat et al., 2015) and the promoter region of tumor necrosis factor-alpha (TNF- $\alpha$ ) gene (Lendez et al., 2015). However, these factors cannot fully explain LPL profile. Even though humoral immune

\footnotetext{
* Corresponding author.

E-mail address: gdolcini@vet.unicen.edu.ar (G.L. Dolcini).
} 
Table 1

Monoclonal antibodies used for differentiation and labeling of bovine peripheral blood lymphocytes applying flow cytometry.

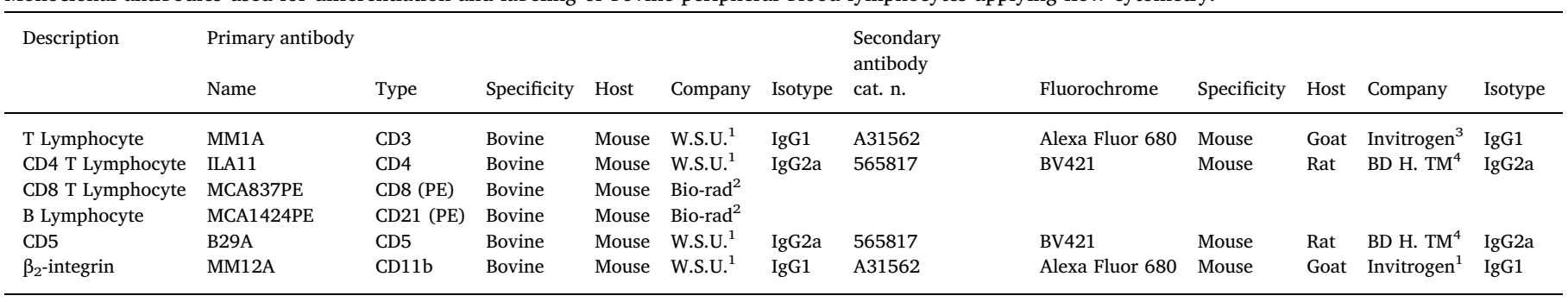

PE: R-Phycoerythrin; ${ }^{1}$ Washington State University, Pullman, WA, USA; ${ }^{2}$ Bio-rad, Raleigh, USA; ${ }^{3}$ Invitrogen, Carlsbad, CA, USA; ${ }^{4}$ BD Horizon TM, Piscataway, USA.

responses were described (Juliarena et al., 2007), cellular response against the virus has not been well characterized in animals that develop LPL or HPL. Most of the studies carried out the cell dynamics in BLV-infected ewes as a model, nonetheless there is great difference between cattle and ewes in BLV-infection (Florins et al., 2007). To the best of our knowledge, no study has been carried out yet on lymphocyte proliferation and apoptosis of different lymphocyte subpopulations in dairy cows infected with BLV with distinct proviral loads.

BLV infection alters immunological mechanisms, mainly affecting Blymphocytes; moreover, BLV can also infect and alter other cell types, particularly T-cells (Gillet et al., 2007; Florins et al., 2007; Kabeya et al., 2001; Frie and Coussens, 2015). While polyclonal proliferation of B-cells is likely one factor leading to dramatic alterations in the relative percent of other cell types in peripheral blood mononuclear cells (PBMCs), other factors must be considered, such as the rate of proliferation and apoptosis in various immune cells. Evidence in the literature suggest that both cellular proliferation and apoptosis rates are altered in BLV-infected cattle, though there is no consensus on the direction of these changes (Klener et al., 2006; Erskine et al., 2011; Souza et al., 2011; Frie and Coussens, 2015).

To deepen our knowledge on BLV effects on immune lymphocyte responses, our study attempts to explore the proliferation and apoptosis of distinct lymphocyte subpopulations in clinically healthy BLV-infected cows that sustained different proviral load profiles.

\section{Materials and methods}

\subsection{Animals}

Twenty-four adult Holstein dairy cattle were used: eight animals were classified as BLV-negative or uninfected and 16 animals were classified as BLV-positive animals using the ELISA 108 (Gutierrez et al., 2001). All lactating dairy cows were clinically healthy and between the second and third lactations. Cows around parturition were excluded. The proviral load was determined by real-time PCR as described previously (Farias et al., 2016) and evaluated two times at six-month intervals before classifying BLV-positive animals into the high proviral load, HPL, $\mathrm{n}=8$ ( $>1000 \mathrm{BLV}$ copies/reaction) or into the low proviral load, LPL, $\mathrm{n}=8$ ( $<100 \mathrm{BLV}$ copies/reaction) group. Once animals were re-tested and classified into the different groups, trials were carried out.

\subsection{PBMCs culture and proliferation assay}

Peripheral venous blood samples were collected in tubes containing sodium citrate/EDTA. PBMCs were isolated by Ficoll-Paque ${ }^{\mathrm{TM}}$ PLUS density gradient (GE Healthcare, Sigma-Aldrich, Darmstadt, Germany). PBMCs were suspended in RMPI 1640 (Gibco, Thermo Fisher, Massachusetts, USA) with $10 \%$ heat-inactivated fetal calf serum (FCS) supplemented with penicillin and streptomycin. PBMCs $\left(3 \times 10^{5}\right.$ cells per well) were cultured for $48 \mathrm{~h}$ in triplicate wells of 96-well culture cluster (Corning, USA) in the presence of different mitogens:
Concanavalin A (ConA, Sigma-Aldrich, Darmstadt, Germany; $10 \mathrm{ng} /$ $1 \times 10^{6} \mathrm{PBMCs}$ ), lipopolysaccharides from Escherichia coli 026:B6 (LPS, Sigma-Aldrich, Darmstadt, Germany; $\left.19 \mu \mathrm{g} / 1 \times 10^{6} \mathrm{PBMCs}\right)$, Pokeweed mitogen (PWM, Sigma-Aldrich, Darmstadt, Germany; $100 \mathrm{ng} / 1 \times 10^{6}$ PBMCs), or without mitogen (control cells). Con-A was used for mithogen-induce proliferation of T lymphocytes (Soder and Holden, 1999; Mehrzad and Zhao, 2008), LPS was used to induce B cells (Mond and Brunswick, 2003; Mehrzad and Zhao, 2008; Latorre et al., 2009), and PWM was used to induce both T- and B- cells (Vries et al., 1980).

The methodology used for cell proliferation assay was similar to that described by Erskine et al., (2011), but with modifications in mitogens concentration, cell culture conditions and metabolite quantification. We measured cell proliferation by 3-(4,5 dimethylthiazol-2-yl) 2,5diphenyltetrazole (MTT, Sigma-Aldrich, Darmstadt, Germany) reduction assay, quantifying the absorbance of formazan crystals in a spectrophotometer at $490 \mathrm{~nm}$ (Mosmann, 1983), at conditions set up in our laboratory.

\subsection{Flow cytometry analysis}

\subsubsection{Identification of lymphocyte subpopulations}

Aliquots of blood $(100 \mu \mathrm{L})$ were hypotonically lysed twice, using $0.2 \% \mathrm{NaCl}$ for approximately $20 \mathrm{~s}$ followed by addition of $1.6 \% \mathrm{NaCl}$ to eliminate contaminating erythrocytes. After centrifugation at $250 \mathrm{x} \mathrm{g}$ for $8 \mathrm{~min}$, the cells were washed, resuspended in PBS supplemented with $1 \%(\mathrm{v} / \mathrm{v})$ FCS and incubated for $30 \mathrm{~min}$ with a mix of the following primary monoclonal antibodies (mAbs) CD3, CD4 and CD8, and CD21, CD5 and CD11b. After incubation, $1 \mathrm{~mL}$ of PBS was added to the cell suspension and centrifuged at $250 \mathrm{x} g$ for $8 \mathrm{~min}$. Then, cells were incubated for $30 \mathrm{~min}$ at room temperature with the labelled secondary Abs resuspended in PBS/1\% (v/v) FCS. Antibodies used are described in Table 1. After the second incubation, cells were washed with PBS with $0.1 \%(\mathrm{v} / \mathrm{v})$ bovine serum albumin and promptly analyzed by flow cytometry (BD FACSCanto II, Becton Dickinson Immunocytometry System $^{\text {Tw }}$, San Diego, USA). Here, 20.000 cells, excluding most of the cellular debris, were analyzed. An unstained control and single-stained samples were also prepared as compensation controls. Negative control samples were also stained with conjugated isotype control antibodies. In addition, cells were stained with fluorescence minus-one (FMO) controls. Our gating strategy analysis for B-lymphocytes subsets are shown in supplemental Figure S1. Obtained data was analyzed with FlowJo software (TreeStar Inc., Ashland, OR, USA). The percentages of B- and T-lymphocytes were determined within gated peripheral blood mononuclear cells, and their subpopulations were assessed within gated $\mathrm{B}$ - or T-cells, respectively. The T-lymphocytes were divided into: $\mathrm{T}$ $\mathrm{CD}^{+}, \mathrm{T} \mathrm{CD}^{+}$and $\mathrm{T} \mathrm{CD}^{-} / \mathrm{CD}^{-}$.

\subsubsection{Detection of apoptosis by flow cytometry}

The viability of B and T lymphocytes, and their subpopulations, was evaluated using dual labeling with an annexin-V FITC antibody (556547, BD Biosciences, San Diego, USA) and 7-aminoactinomycin (7AAD; 420404, Biolend, San Diego, USA). Blood cells were labelled using 
mAbs as described above. To analyze the data, scatter plots were generated for the gated $\mathrm{B}$ and $\mathrm{T}$ cells, and their subpopulations. The nonapoptotic cells were negative for the FITC-labeled annexin $\mathrm{V}$ and 7-AAD staining. Cells that were reactive to FITC-labeled annexin V but negative for 7-AAD were classified as apoptotic. Finally, the cells that were reactive for both FITC-labeled annexin $\mathrm{V}$ and 7-ADD were classified as late apoptotic or necrotic.

\subsubsection{Statistics analysis}

For statistics analysis of results, the INFOSTAT (Córdoba, Argentina) software was used. In cell proliferation assays, stimulation index was calculated as the relative absorbance of mitogen-stimulated cells divided by the absorbance of unstimulated (control) cells within each group. For flow cytometry results, the normal distribution of data was evaluated with the Kolmogorov test, and differences between groups were evaluated using ANOVA followed by Tukey test. Results are reported as means $\pm \mathrm{SD}$. A value of $P \leq 0.05$ was considered significant.

\section{Results}

\subsection{HPL animals proliferate more than $L P L$ and $B L V$-uninfected animals}

When comparing infected versus with uninfected animals, the first group showed statistically significant differences with all the tested stimuli: ConA $(P=0.002)$, PWM $(P=0.007)$, LPS $(P=0.0008)$ (Fig. 1A). A higher proliferative response was observed in HPL animals compared to LPL, when stimulated with the mitogens ConA $(P=0.01)$, PWM $(P=0.03)$ and LPS $(P=0.01)$. When BLV-uninfected and HPL animals were compared, the BLV-uninfected dairy cows showed lower lymphocyte proliferation stimulation index with all stimuli (ConA, $P=$ 0.0007; PWM, $P=0.004$; LPS, $P=0.0007$ ). However, when BLVuninfected animals were compared with the LPL group, the proliferation response was more evident in the latter group. Proliferation rates in LPL group were higher when stimulating with ConA $(P=0.02), \mathrm{PWM}$ $(P=0.045)$ and LPS $(P=0.002)$ (Fig.1B).

3.2. Percentages of total B-and T-lymphocytes and their subpopulations in $B L V$ infected animals with HPL and LPL, and BLV-uninfected animals

The percentages of B-lymphocytes $\mathrm{CD} 21^{+}$, and its subpopulations

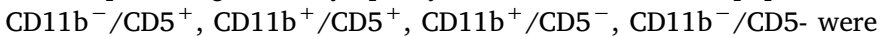
evaluated by flow cytometry. The analysis of flow cytometry in PBMCs from HPL, LPL and uninfected animals showed that HPL animals had a higher percentage of $\mathrm{B}$ cells $(P=0.01)$ and $\mathrm{CD} 11 \mathrm{~b}^{-} / \mathrm{CD}^{+} \mathrm{B}-\mathrm{lym}-$ phocytes $(P=0.005)$, compared to LPL and uninfected cattle. Also, a

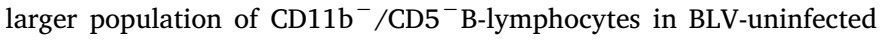
animals compared to HPL animals $(P=0.003)$ (Fig. $2 \mathrm{~A})$ was found.

When a similar analysis is performed with T-lymphocytes both the BLV-uninfected cattle and the LPL group presented a higher percentage of $\mathrm{CD}^{+}$lymphocytes than those of HPL group $(P=0.01)$. Similar results were observed in $\mathrm{CD} 4^{+}$T-cells $(P=0.01)$. However, concerning the CD8 + T-lymphocytes, this greater difference was only observed in LPL animals compared to HPL $(P=0.01)$. The percentages of $\mathrm{T} \mathrm{CD}^{-} /$ CD8- lymphocytes had no significant differences between the groups studied (Fig. 2B).

\subsection{B-lymphocytes present greater early apoptosis rates in $B L V$-uninfected} dairy cows than HPL animals

As expected, the B-lymphocyte subpopulations of PBMCs from HPL animals had a much lower percentage of cells exhibiting early apoptosis, which is related to the viability results detailed below. As shown in Fig. 3A, B-lymphocytes $(P=0.009)$ and its subpopulations $\mathrm{CD}^{-11 \mathrm{~b}^{-}}$/ $\mathrm{CD}^{+}(P=0.007)$ and $\mathrm{CD}^{+} 1 \mathrm{~b}^{+} / \mathrm{CD}^{+}(P=0.005)$ presented significant lower early apoptosis rates than BLV-uninfected dairy cows (Fig. 3A). Concerning early apoptosis in T-cell subpopulations, no significant differences between groups were found (Fig. 3B).

\subsection{Increased late apoptosis in $C D 11 b+/ C D 5+B$-lymphocytes in $L P L$ animals}

Coincidentally, B CD11b $\mathrm{b}^{+} / \mathrm{CD}^{+}$lymphocytes from LPL animals had both higher early and late apoptosis $(P=0.03)$ than HPL animals. In the case of BLV-uninfected animals, they had higher late apoptosis compared to HPL animals in B cells $(P=0.03)$ (Fig. 4A). Related to the cellular subpopulations of T-lymphocytes which are mainly in late apoptosis, we did not find statistically significant differences between the groups (Fig. 4B).

\subsection{Increased viability in B-lymphocyte subpopulations in HPL animals compared to LPL and BLV-uninfected dairy cows}

Differences were found between HPL and LPL animals: the cells of the former are more viable than the latter in the following lymphocyte populations: B lymphocytes $(P=0.003)$ and $\mathrm{B} \mathrm{CD}_{11 \mathrm{~b}}{ }^{+} / \mathrm{CD}^{+}(P=$ 0.004 ) cells. Also, differences were found between HPL and BLV-uninfected animals: B-lymphocytes $(P=0.003)$ and its subpopulations $\mathrm{CD} 11 \mathrm{~b}^{-} / \mathrm{CD}^{+}(P=0.0001), \mathrm{B} \mathrm{CD}^{+} 1 \mathrm{~b}^{+} / \mathrm{CD}^{+}(P=0.004)$ and $\mathrm{B}$ $\mathrm{CD}_{11 \mathrm{~b}^{-}} / \mathrm{CD}^{-}(P=0.04)$. In the case of the LPL animals, the $\mathrm{B}$ CD11b-/CD5 + cells were negative for Annexin-V FITC and 7-AAD (non-apoptotic) compared to BLV-uninfected cattle $(P=0.0001)$ (Fig. 5A). Regarding the viability of T-lymphocytes and its subpopulations, there were no significant differences between groups (Fig. 5B).

\section{Discussion}

Although BLV infection causes EBL only in less than $10 \%$ of infected animals, recent studies suggest that it causes more negative effects on the herd than previously believed. BLV interferes with the production and performance of infected animals, and there are abnormalities in the immunity of these animals (Frie and Coussens, 2015). Several studies have focused on studying the abnormalities in cell proliferation, which would lead to PL, finding differences in the ovine experimental model related to the natural BLV host (Florins et al., 2008). Currently all the studies were studied in lymphocyte proliferation in naturally BLV-infected dairy cows, PL and non-PL animals (Erskine et al., 2011; Souza et al., 2011). No study has regarded the different BLV proviral load that may bias the previous findings, as a significant proportion of AL dairy cows showed HPL as animals with PL (Juliarena et al., 2007). As far as we know, the present study is the first one concerning cell proliferation and apoptosis developed in naturally infected cattle, considering their proviral load.

In vitro studies using mitotic stimuli on lymphocytes are aimed to evaluate their functionality, and cells usually respond by producing cytokines, expressing cytokine receptors, and ultimately, proliferating. In our assays, mitogens were selected based on their proliferation effect on different lymphocyte subpopulation: LPS and PWM mitogens both stimulate B-lymphocytes, while ConA stimulates T-cells. Stimulated PBMCs from HPL animals proliferate more than those from LPL and BLV-uninfected cattle; and in turn, cells from infected animals proliferate more than those from uninfected. When LPS and PWM mitogens were used, the same groups had the same behavior as when ConA was used. We could conclude that PBMCs from HPL animals are more sensitive to cell proliferation when stimulated in vitro with different mitogens. Sordillo et al. showed previously that lymphocytes from PL cattle had lower proliferative responses to ConA or PWM, compared with cells from AL or BLV-uninfected animals (Sordillo et al., 1994). Other data from the literature describe that, when stimulating with ConA, cells from negative animals have greater proliferation when compared with those from PL, and concerning stimulation with PWM, cells from AL animals proliferate more than those from PL and uninfected animals (Erskine et al., 2011). Differences in results might come 

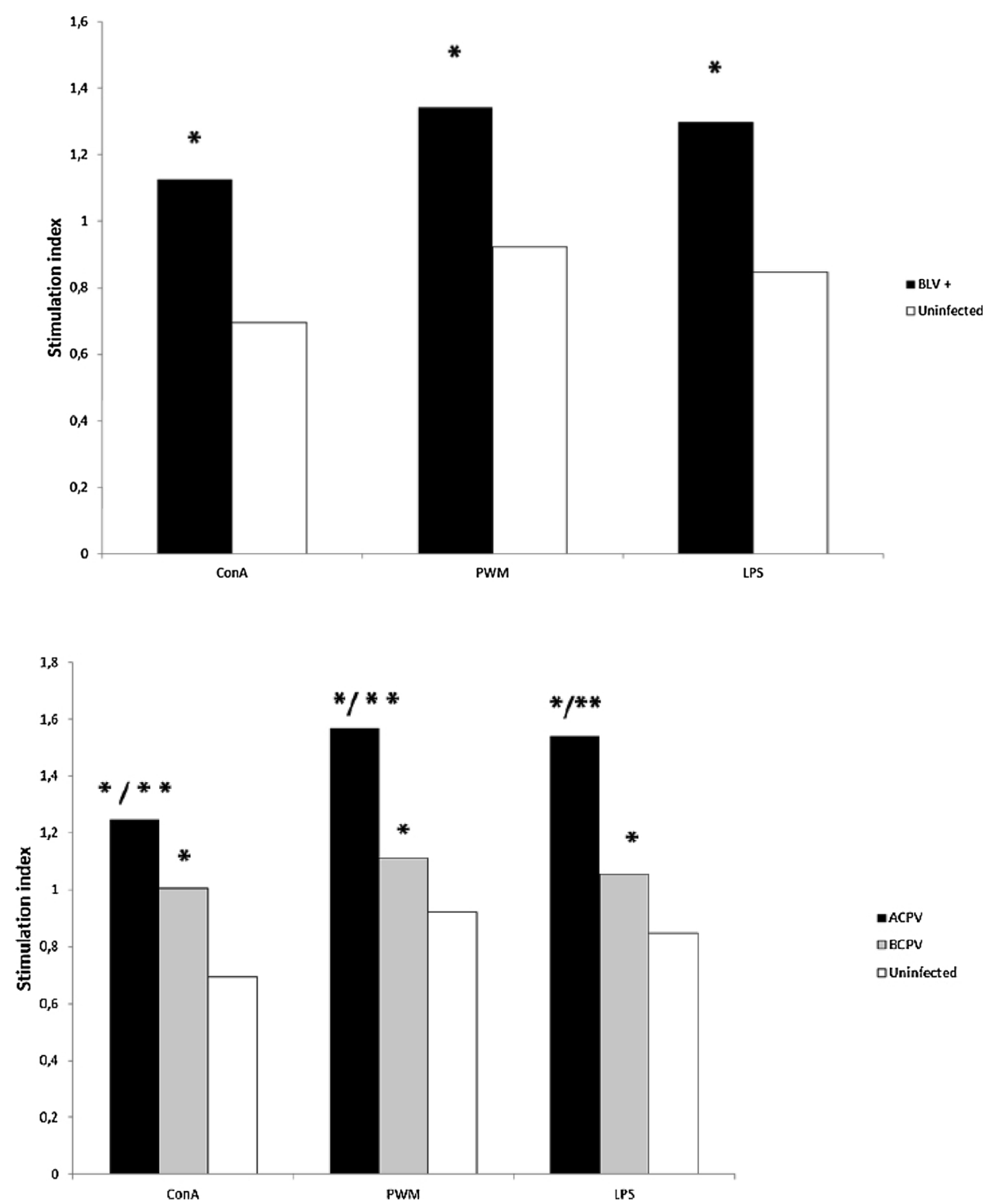

Fig. 1. Mean \pm SEM lymphoproliferative response to mitogens from PBMCs isolated from: (A) BLV-infected animals (BLV +) and BLV-uninfected animals (BLV-); (B) in HPL, LPL and BLV-. One asterisk (*) indicates significant statistical differences $(P<0.05)$ related to the uninfected control; two asterisks $(* *)$ indicate statistically significant differences $(P<0.05)$ related to LPL.

from different concentration of mitogens used in the in vitro studies. Besides, we classify animals in terms of their proviral load, and the group with HPL may include AL animals.

In our work, HPL animals have grater proliferation with and without stimuli in culture than the others groups. Our results might agree with those from Konnai et al., who reported spontaneous cell proliferation in PBMCs from BLV-infected cattle with high percentage of BLV-infected cell and with lymphosarcoma, and non-spontaneous cell proliferation in PBMCs derived from cattle with low percentage of BLV-infected cells or BLV-uninfected cattle (Konnai et al., 2006).

BLV-infected animals often show abnormal ratios of cell populations in comparison to healthy animals: significantly higher relative B-cell percentages and significantly lower relative T-cell percentages, including lower percentages of $\mathrm{CD}^{+}, \mathrm{CD}^{+}$and $\mathrm{CD}^{+}$cells (Erskine et al., 2011; Sordillo et al., 1994; Van den Broeke et al., 2010) and a higher ratio of $\mathrm{CD}^{+}: \mathrm{CD} 8^{+} \mathrm{T}$ cells (Stone et al., 1995) than uninfected controls. Based on proviral load, we found that HPL animals have a significantly lower percentage of T-cells, both $\mathrm{CD}^{+}{ }^{+}$and $\mathrm{CD}^{+}$cells. Therefore, when stimulated with ConA, PBMCs from these animals tend to proliferate less than those from LPL or negative animals. As we observed that HPL animals have a higher percentage of B-cells, this could explain why PBMCs proliferate more with LPS and PWM, compared to the other two groups. Indeed, BLV primarily infects B-cells (Meiron et al., 1997) and $66 \%$ of $\mathrm{CD}^{+}$B-cells carried the provirus (Mirsky et al., 1996). So, as others authors suggested (Frie et al., 2017), our results could indicate that infected B-cells proliferate in response to immune stimulation. A key factor to be taken into account is BLV reactivation when infected cell are in vitro cultured (Florins et al., 2007). Even though whole PBMCs were evaluated, the high rates of proliferation seen in our study could come from B-lymphocytes, which may also proliferate due to virus reactivation in culture.

Programmed cell death (apoptosis) is a biological process for the normal functioning of the immune system. When this mechanism is altered due to BLV infection, the homeostasis of lymphocyte populations is altered (Debacq et al., 2003; Florins et al., 2008). Several studies on cell dynamics and apoptosis were carried out in experimentally BLV-infected sheep (Chevallier et al., 1998; Debacq et al., 2002; Florins et al., 2009). Moreover, concerning the natural host for the virus, most 


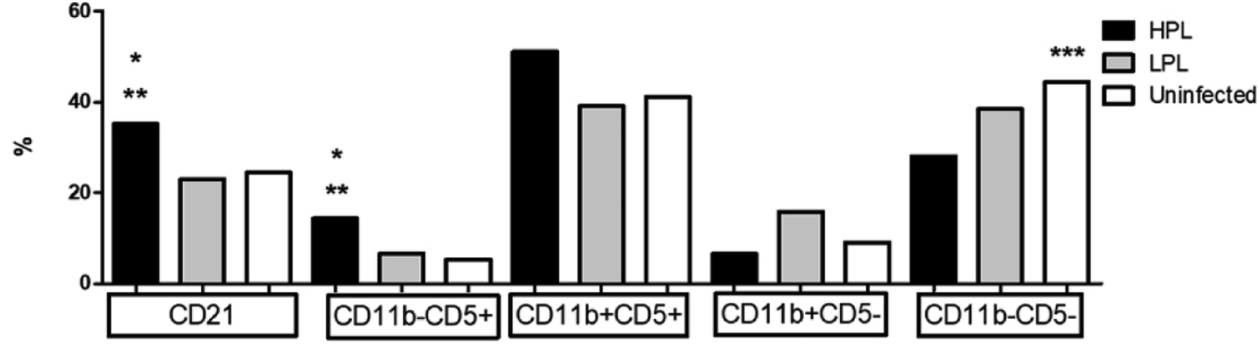

Fig. 2. Percentage of B-lymphocytes (A) or Tlymphocytes (B) and its subpopulations from BLV-uninfected and BLV-infected animals with low proviral load (LPL) and high proviral load (HPL). One asterisk (*) indicates significant difference to BLV-uninfected animals $(P<0.05)$; two asterisks $(* *)$ indicate statistically significant differences to LPL animals $(P<0.05)$; three asterisks $(* * *)$ indicate statistically significant differences to HPL animals $(P<0.05)$.

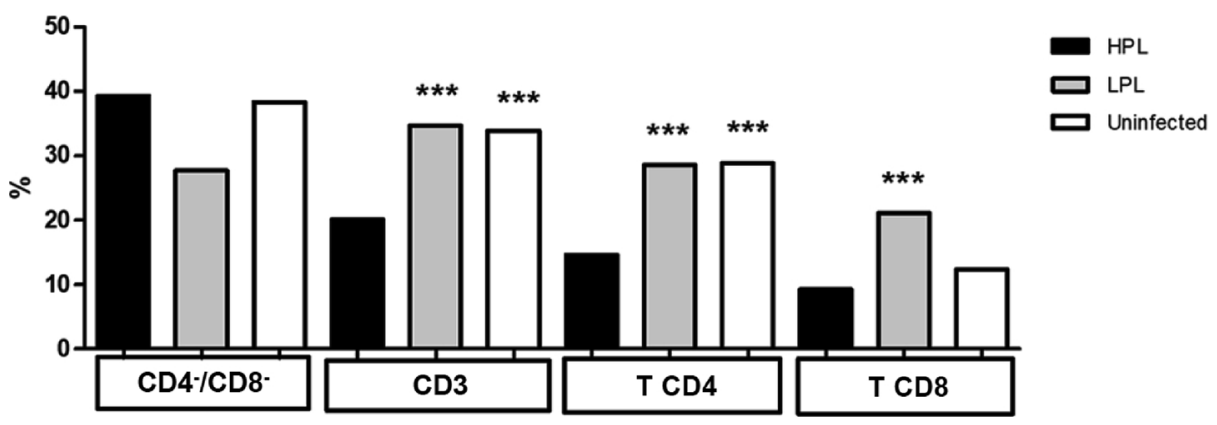

studies were done in vitro, on cultured cells, and showed an increased apoptosis rates in B-cells from AL cows (Cantor et al., 2001; Debacq et al., 2003). On studies demonstrated that freshly isolated B-cells do not have significantly different rates of apoptosis between uninfected and BLV-infected cattle (Erskine et al., 2011). On the contrary, Souza observed a lower lymphocyte proliferation in the animals of the LP group associated with the reduction of $\mathrm{CD}^{+}$cell apoptosis (Souza et al., 2011). We evaluated, for the first time, B- and T-lymphocytes subpopulations, from uninfected and BLV-infected animals classified according to their proviral load, in terms of their percentage in peripheral blood and its stage of apoptosis and viability. Data from the literature suggest that the target cell for $\mathrm{BLV}$ is $\mathrm{MHCII}^{+}, \mathrm{IgM}^{+}, \mathrm{CD}^{+}$ and $\mathrm{CD} 11 \mathrm{~b}^{+}$with some fluctuations for the three latter markers at late stages of the disease (Gillet et al., 2007). We show that the percentage of $\mathrm{CD} 11 \mathrm{~b}^{+} / \mathrm{CD}^{+}$cells is increased in HPL animals compared to LPL and no infected animals, although without significant differences. Della Libera et al. indicate that BLV infected animals have increased values for CD21, CD5 and CD11b markers (Della Libera et al., 2012), phenomena that might be related to the modulation of apoptosis in these cells (Souza et al., 2011). As in humans and mice, bovine CD5 molecule
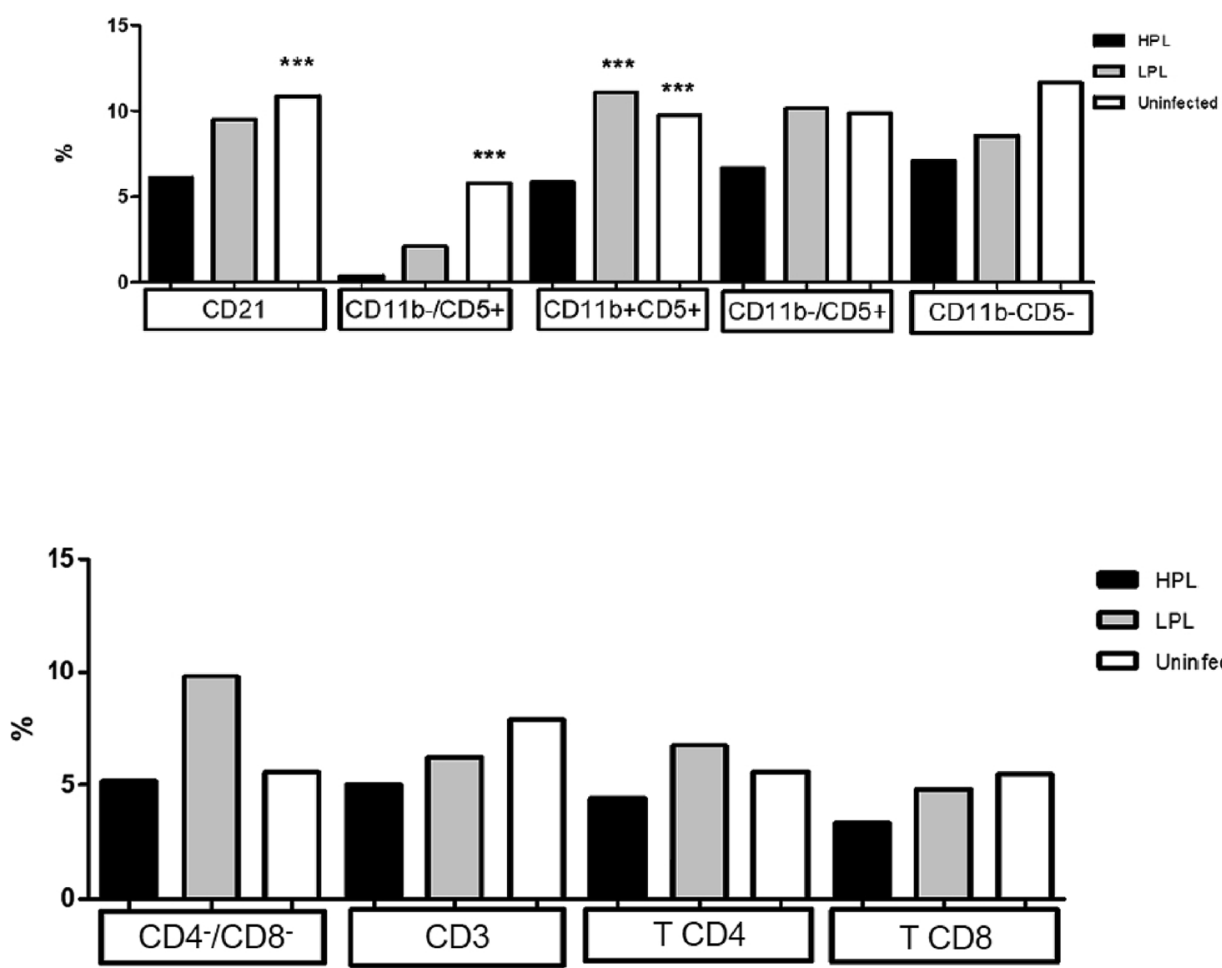

Fig. 3. Percentage of early apoptosis in Blymphocytes (A) or in T-lymphocytes (B) and their subpopulations from BLV-uninfected and BLV-infected animals with low proviral load (LPL) and high proviral load (HPL). One asterisk $\left(^{*}\right)$ indicates significant difference compared to not infected animals $(P<0.05)$; two asterisks $(* *)$ indicate statistically significant differences to LPL animals $(P<0.05)$; three asterisks $(* * *)$ indicate statistically significant differences to HPL animals $(P<0.05)$. 

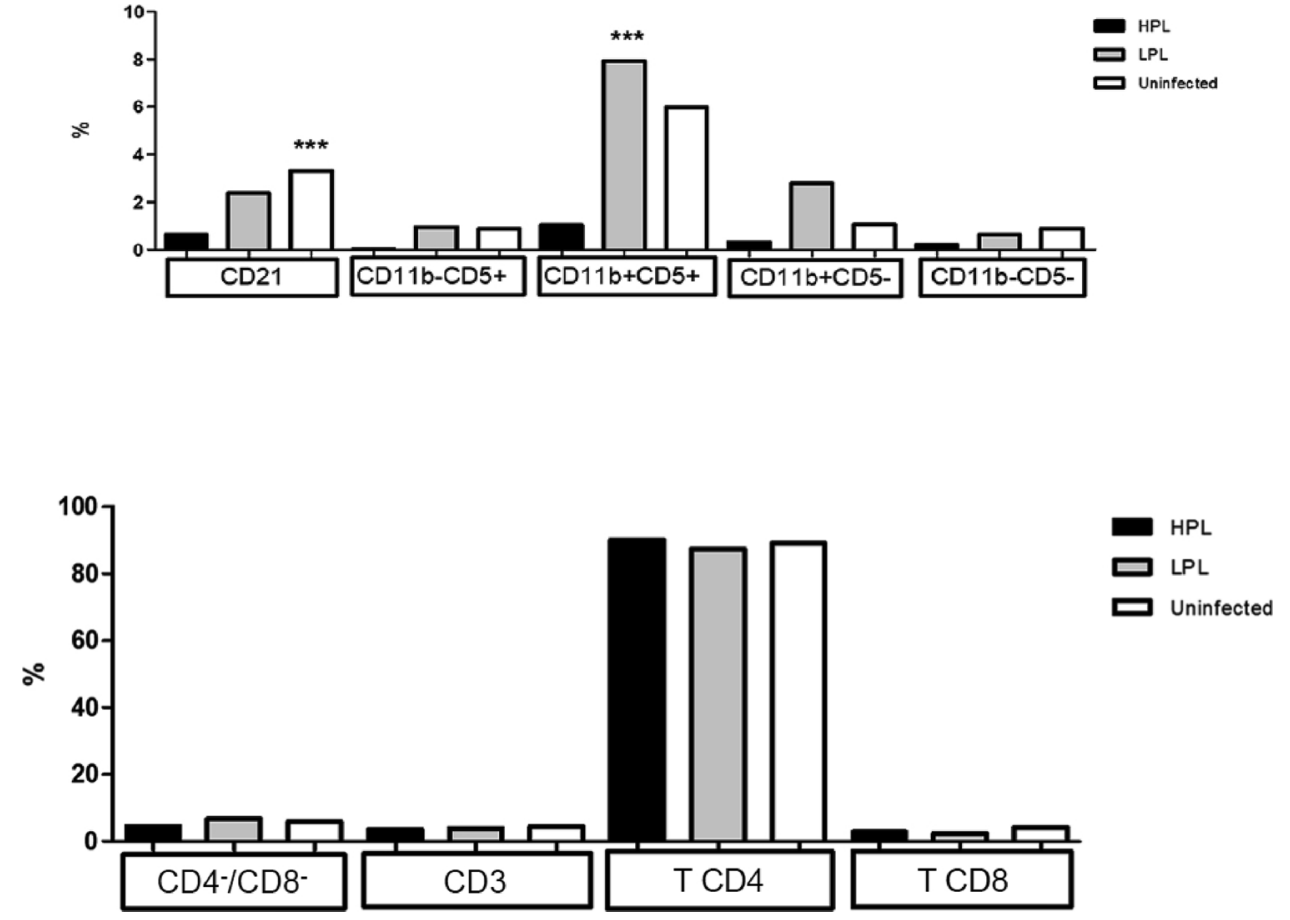

Fig. 4. Percentage of late apoptosis in B-lymphocytes (A) or in T-lymphocytes (B) and their subpopulations from BLV-uninfected and BLVinfected animals with low proviral load (LPL) and high proviral load (HPL). One asterisk (*) indicates significant difference related, compared, to not infected animals $(P<0.05)$; two asterisks $(* *)$ indicate statistically significant differences to LPL animals $(P<0.05)$; three asterisks $(* * *)$ indicate statistically significant differences to HPL animals $(P<0.05)$. is present in most T-cells but only in a small number of normal B-cells; however, in BLV-infected PL cattle, nearly all of the B-cells are CD5 ${ }^{+}$ (Depelchin et al., 1989). In B-cells from uninfected animals, CD5 ${ }^{+}$associates with the $\mathrm{B}$-cell receptor (BCR), and this crosslinking decreases apoptosis of $\mathrm{CD}^{+} \mathrm{B}$-cells. However, CD5 is dissociated from de BCR in B-cells from PL cattle and it was suggested that subsequent decreased apoptosis in antigenically stimulated B-cells may thus be a mechanism of BLV induced PL (Hamilton et al., 2003; Gillet et al., 2007). Another marker, the CD11b integrin molecule, was also observed in infected animals from several studies (Gillet et al., 2007). In our study,

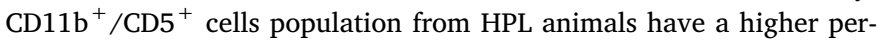
centage of cell viability with respect to the other two groups, which is accompanied by a decrease in early and late apoptosis. These results would be in accordance with data from the literature, where lymphocyte immune phenotyping of BLV-infected cows with PL had an increase in B-cells, mainly B CD5 ${ }^{+} / \mathrm{CD}_{11 \mathrm{~b}^{+}}$, due to apoptosis inhibition (Blagitz et al., 2017). Moreover, Erskine et al. showed that PL animals have an increased expression of the anti-apoptotic gene Bcl2, and AL animals had higher expression of the pro-apoptotic gene Bcl2L1 (Erskine et al., 2011).

When analyzing the other B-cell subpopulations, the markers that are increased in HPL animals compared to non-infected animals are

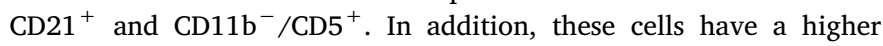
percentage of viability, and a decrease in early apoptosis. This could be
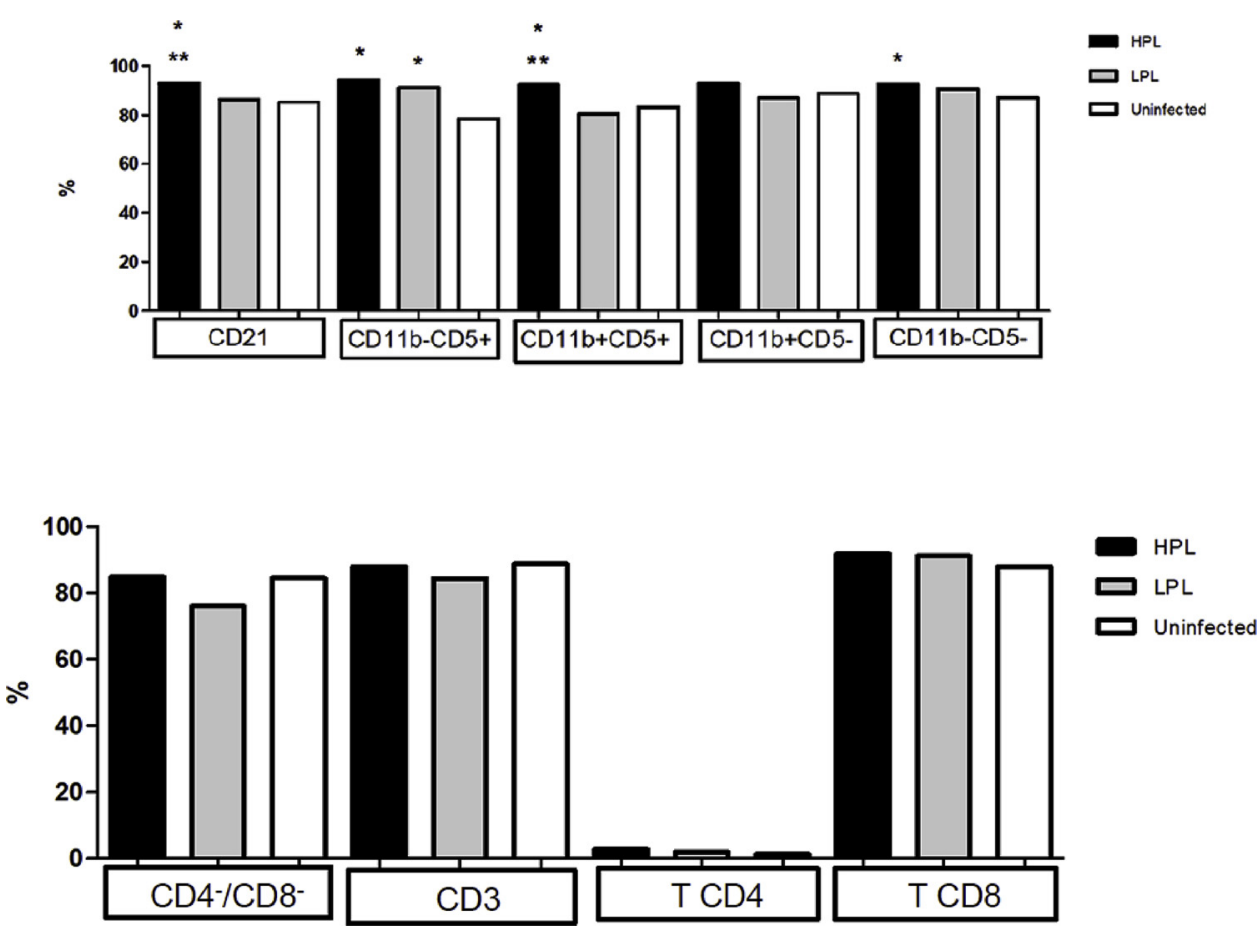

Fig. 5. Percentage of viability in B-lymphocytes (A) or in T-lymphocytes (B) and their subpopulations from BLV-uninfected and BLVinfected animals with low proviral load (LPL) and high proviral load (HPL). One asterisk (*) indicates significant difference to not infected animals $(P<0.05)$; two asterisks $(* *)$ indicate statistically significant differences to LPL animals $(P<0.05)$; three asterisks $(* * *)$ indicate statistically significant differences to HPL animals $(P<0.05)$. 
a manifestation that BLV infection also alters the balance of cell death and proliferation in other lymphocyte populations such as $\mathrm{CD} 21^{+}$and

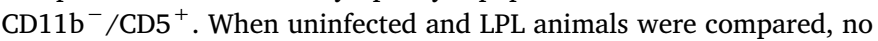
differences in the viability, total percentage and apoptosis were found in $\mathrm{CD} 11 \mathrm{~b}^{+} / \mathrm{CD}^{+}$and $\mathrm{CD} 21^{+}$cells. On the contrary, we observed a slight increase in the percentage of cell viability of the CD11b ${ }^{-} / \mathrm{CD} 5-$ cells in LPL animals.

Our results show that HPL animals have an imbalance in terms of programmed cell death and cell viability in cells that are target of BLV. In fact, LPL animals have increased apoptosis rates in this cellular subpopulation. In turn, the main difference between BLV-uninfected and LPL animals is that the latter have a higher percentage of late apoptosis compared to HPL. Therefore, this could be specifically the way by which LPL animals control the progression of the disease.

Regarding population of T-lymphocytes, other authors showed that PL animals have a lower counting in the absolute number of T-cells, both $\mathrm{CD} 4+$ and $\mathrm{CD} 8+$, in comparison with AL or uninfected animals (Gatei et al., 1989). However, Della Libera et al. described no significant changes in the absolute numbers of CD4 + and CD8 + T-lymphocytes in PL animals, but with a lower percentage of both subsets (Della Libera et al., 2012). In this way, we found that LPL animals have a higher percentage of $\mathrm{CD} 3+, \mathrm{CD} 4+$ and $\mathrm{CD} 8+\mathrm{T}$-lymphocytes than HPL animals.

The proportion of $\mathrm{CD}^{+}$and $\mathrm{CD} 8^{+} \mathrm{T}$ cells can be related to the differential secretion of cytokines in the groups of animals. Indeed, cytokines expression in response to BLV infection is deregulated, with a prevalence of a Th1 profile observed in animals with lymphosarcoma and PL. This imbalance and suppression of T-cell proliferation in response to BLV antigens are considered to be associated with disease progression (Orlik and Splitter, 1996; Trainin et al., 1996; Pyeon and Splitter, 1998; Yakobson et al., 2000; Kabeya et al., 2001; Frie and Coussens, 2015). Our previous studies showed that expression of IFN- $\gamma$ (Th1 cytokine) is higher in LPL animals (Farias et al., 2016), indicating a protective role of IFN- $\gamma$ in the pathogenesis of BLV infection. This cytokine mediates the activation of NK cells, monocytes/macrophages and dendritic cells; it promotes the differentiation of $\mathrm{CD} 4{ }^{+} \mathrm{T}$-cells into a Th1 profile and the activation of $\mathrm{T} \mathrm{CD}^{+}$cells, in favors of the development of an effective antiviral immunity. In turn, as a positive feedback, IFN- $\gamma$ is secreted by $\gamma \delta^{+}$T-cells and NK cells, CD4 ${ }^{+}$Th1 cells and cytotoxic $\mathrm{CD} 8^{+} \mathrm{T}$-cells, monocytes/macrophages and dendritic cells (Schroder et al., 2004). The largest proportion of $\mathrm{CD}^{+}{ }^{+}$and $\mathrm{CD} 8^{+}$ $\mathrm{T}$ lymphocytes found in our LPL animals reinforces the concept of a better capability of these animals to eradicate/control BLV infection, may be via strong cytotoxic responses positively regulated by IFN $-\gamma$. As mentioned, $\gamma \delta^{+}$T-cells and NK cells are major IFN- $\gamma$ sources and they have also cytotoxic functions. Clevers et al. defined the bovine T CD4-/ CD8- population as $\gamma \delta^{+}$T-lymphocytes (Clevers et al., 1990). It has been described that the state of AL in BLV infection is related to a greater proportion of $\gamma \delta^{+}$T-lymphocytes (Lundberg and Splitter, 2000). However, in our study no differences were found in the percentage of T CD4-/CD8- population. Thus, the higher expression of IFN$\gamma$ mRNA found in LPL animals (Farias et al., 2016) might not come from those cells, but it could be related to a greater cytotoxic $\mathrm{CD}^{+}$cell, NK cell or professional antigen-presenting cell percentage in these animals.

LPL animals presented a higher percentage of apoptosis in $\mathrm{CD}_{11} \mathrm{~b}^{+}$/ $\mathrm{CD}^{+}$B-lymphocytes, which are the primary targets for BLV integration (Meiron et al., 1997). These data, in turn, are related to the high percentage of viability of the B subpopulations of LPL animals. This reinforces the concept that LPL animals have an anti-apoptotic and proliferative status.

Our work confirmed that BLV infection alters cellular homeostasis, and it turns in a deficiency of the immune system in infected animals. Indeed, in agreement with our findings, a functional exhaustion of $\mathrm{CD}^{+}{ }^{+}$and $\mathrm{CD}^{+}{ }^{+} \mathrm{T}$ cells, associated to disease development has been demonstrated (Okagawa et al., 2018). Thus, infected animals are less competent to fight against other diseases, which generates significant economic losses. The only way to eradicate BLV infection would be to sacrifice positive animals. As there are no economic compensation policies in our country, we suggest that one way to control the infection would be replacing HPL animals with LPL animals since they behave like "controlling animals". At the same time, it would be interesting to know which proteins are involved in the apoptosis of these animals, in order to accurately identify how the BLV alters its target cells.

\section{Conflict of interest statement}

The authors declared no potential conflicts of interest with respect to the research, authorship, publication of this article and/or financial and personal relationships that could inappropriately influence this work.

\section{Appendix A. Supplementary data}

Supplementary material related to this article can be found, in the online version, at doi:https://doi.org/10.1016/j.vetimm.2018.10.012.

\section{References}

Bartlett, P.C., Norby, B., Byrem, T.M., Parmelee, A., Ledergerber, J.T., Erskine, R.J., 2013. Bovine leukemia virus and cow longevity in Michigan dairy herds. J. Dairy Sci. 96, 1591-1597.

Blagitz, M.G., Souza, F.N., Batista, C.F., Azevedo, L.F.F., Sanchez, E.M.R., Diniz, S.A., Silva, M.X., Haddad, J.P., Della Libera, A.M.M.P., 2017. Immunological implications of bovine leukemia virus infection. Res. Vet. Sci. 114, 109-116.

Cantor, G.H., Pritchard, S.M., Dequiedt, F., Willems, L., Kettmann, R., Davis, W.C., 2001. CD5 is dissociated from the B-cell receptor in B cells from bovine leukemia virusinfected, persistently lymphocytotic cattle: consequences to B-cell receptor-mediated apoptosis. J. Virol. 75 (4), 1689-1696.

Chevallier, N., Berthelemy, M., Le Rhun, D., Laine, V., Levy, D., Schwartz-Cornil, I., 1998. Bovine leukemia virus-induced lymphocytosis and increased cell survival mainly involve the CD11b + B-lymphocyte subset in sheep. J. Virol. 72, 4413-4420.

Clevers, H., MacHugh, N.D., Bensaid, A., Dunlap, S., Baldwin, C.L., Kaushal, A., Iams, K., Howard, C.J., Morrison, W.I., 1990. Identification of a bovine surface antigen uniquely expressed on CD4-CD8- T cell receptor gamma/delta + T lymphocytes. Eur. J. Immunol. 20, 809-817.

Debacq, C., Asquith, B., Kerkhofs, P., Portetelle, D., Burny, A., Kettmann, R., Willems, L., 2002. Increased cell proliferation, but not reduced cell death, induces lymphocytosis in bovine leukemia virus-infected sheep. PNAS 99 (15), 10048-10053.

Debacq, C., Asquith, B., Reichert, M., Burny, A., Kettmann, R., Willems, L., 2003. Reduced cell turnover in bovine leukemia virus-infected, persistently lymphocytotic cattle. J. Virol. 77, 13073-13083.

Della Libera, A.M.M.P., Blagitz, M.G., Batista, C.F., Latorre, A.O., Stricagnolo, C.R., Souza, F.N., 2012. Quantification of B cells and T lymphocytes subsets in bovine leukemia virus infected dairy cows. Semin-Cienc Agrar 33, 1487-1494.

Depelchin, A., Letesson, J.J., Lostrie-Trussart, N., Mammerickx, M., Portetelle, D., Burny, A., 1989. Bovine leukemia virus (BLV)-infected B-cells express a marker similar to the CD5 T cell marker. Immunol. Lett. 20, 69-76.

Erskine, R.J., Corl, C.M., Gandy, J.C., Sordillo, L.M., 2011. Effect of infection with bovine leucosis virus on lymphocyte proliferation apoptosis in dairy cattle. Am. J. Vet. Res. 72, 1059-1064.

Farias, M.V., Lendes, P.A., Marin, M., Quintana, S., Martínez Cuesta, L., Ceriani, C., Dolcini, G.L., 2016. Toll-like receptors, IFN- $\gamma$ and IL-12 expression in bovine leukemia virus-infected animals with low or high proviral load. Res. Vet. Sci. 107, 190.

Florins, A., Gillet, N., Asquith, B., Boxus, M., Burteau, C., Twizere, J.C., Urbain, P., Vandermeers, F., Debacq, C., Sanchez-Alcaraz, M.T., Schwartz-Cornil, I., Kerkhofs, P., Jean, G., Thewis, A., Hay, J., Mortreux, F., Wattel, E., Reichert, M., Burny, A., Kettmann, R., Bangham, C., Willems, L., 2007. Cell dynamics and immune response to BLV infection: a unifying model. Front. Biosci. 12, 1520-1531.

Florins, A., Boxus, M., Vandermeers, F., Verlaeten, O., Bouzar, A.B., Defoiche, J., Hubaux, R., Burny, A., Kettmann, R., Williems, L., 2008. Emphasis on cell turnover in two hosts infected by bovine leukemia virus: a rationale for host susceptibility to disease Vet. Immunol. Immunopathol. 125, 1-7.

Florins, A., Reichert, M., Asquith, B., Bouzar, A.B., Jean, G., François, C., Jasik, A., Burny, A., Kettmann, R., Willems, L., 2009. Earlier onset of delta-retrovirus-induced leukemia after splenectomy. PLoS One 14, e6943.

Frie, M.C., Coussens, P.M., 2015. Bovine leukemia virus: a major silent threat to proper immune response in cattle. Vet. Immunol. Immunopathol. 163, 103-114.

Frie, M.C., Sporer, K.R.B., Benitez, O.J., Wallace, J.C., Droscha, C.G., Bartlett, P.C., Coussens, P.M., 2017. Dairy cows naturally infected with bovine leukemia virus exhibit abnormal B- and T-Cell phenotypes after primary and secondary exposures to Keyhole limpet hemocyanin. Front. Vet. Sci. 4, 112.

Gatei, M.H., Brandon, R., Naif, H.M., Lawn, M.F., Daniel, C.W., 1989. Lymphosarcoma development in sheep experimentally infected with bovine leukaemia virus. J. Vet. Med. B 36, 424-432.

Gillet, N., Florins, A., Boxus, M., Burteau, C., Nigro, A., Vandermeers, F., Balon, H., 
Bouzar, A.B., Defoiche, J., Burny, A., Reichert, M., Kettmann, R., Willems, L., 2007. Mechanisms of leukemogenesis induced by bovine leukemia virus: prospects for novel anti-retroviral therapies in human. Retrovirology 4, 18.

Gutierrez, S., Dolcini, G., Arroyo, G.H., Rodriguez Dubra, C., Ferrer, J.F., Esteban, E.N., 2001. Development and evaluation of a highly sensitive and specific blocking enzyme-linked immunosorbent assay and polymerase chain reaction assay for diagnosis of bovine leukemia virus infection in cattle. Am. J. Vet. Res. 62, 1571-1577.

Hamilton, V.T., Stone, D.M., Cantor, G.H., 2003. Translocation of the B cell receptor to lipid rafts is inhibited in B cells from BLV-infected, persistent lymphocytosis cattle. Virology 315, 135-147.

Hopkins, S.G., DiGiacomo, R.F., 1997. Natural transmission of bovine leukemia virus in dairy and beef cattle. Vet. Clin. North Am. Food Anim. Pract. 13, 107-128.

Juliarena, M.A., Gutierrez, S.E., Ceriani, C., 2007. Determination of proviral load in bovine leukemia virus-infected cattle with and without lymphocytosis. Am. J. Vet. Res. $68,1220-1225$.

Juliarena, M.A., Poli, M., Sala, L., Ceriani, C., Gutierrez, S., Dolcini, G., Rodriguez, E.M., Marino, B., Rodriguez-Dubra, C., Esteban, E.N., 2008. Association of BLV infection profiles with alleles of the BoLA-DRB3.2 gene. Anim. Genet. 39, 432-438.

Kabeya, H., Ohashi, K., Onuma, M., 2001. Host immune responses in the course of bovine leukemia virus infection. J. Vet. Sci./Jpn. Soc. Vet. Sci. 63, 703-708.

Klener, P., Szynal, M., Cleuter, Y., Merimi, M., Duvillier, H., Lallemand, F., Bagnis, C., Griebel, P., Sotitiou, C., Burny, A., Martiat, P., Van den Broeke, A., 2006. Insights into gene expression changes impacting B-cell transformation: cross-species microarray analysis of bovine leukemia virus tax-responsive genes in ovine B cells. J. Virol. 80, 1922-1938.

Konnai, S., Usui, T., Ikeda, M., Kohara, J., Hirata, T., Okada, K., Ohashi, K., Onuma, M., 2006. Tumor necrosis factor-alpha up-regulation in spontaneously proliferating cells derived from bovine leukemia virus-infected cattle. Arch. Virol. 151, 347-360.

Latorre, A.O., Furlan, M.S., Sakai, M., Fukumasu, H., Hueza, I.M., Haraguchi, M., Górniak, S.L., 2009. Immunomodulatory effects of Pteridiumaquilinum on natural killer cell activity and select aspects of the cellular immune response in mice. J. Immunotoxicol. 6, 104-114.

Lendez, P.A., Passucci, J.A., Poli, M.A., Gutierrez, S.E., Dolcini, G.L., Ceriani, M.C., 2015. Association of TNF-alpha gene promoter region polymorphisms in bovine leukemia virus (BLV)-infected cattle with different proviral loads. Arch. Virol. 160, 2001-2007.

Lundberg, P., Splitter, G.A., 2000. Gammadelta(+) T-Lp6phocyte cytotoxicity against envelope-expressing target cells is unique to the alymphocytic state of bovine leukemia virus infection in the natural host. J. Virol. 74, 8299-8306.

Mehrzad, J., Zhao, X., 2008. T lymphocyte proliferative capacity and $\mathrm{CD} 4^{+} / \mathrm{CD} 8^{+}$ratio in primiparous and multiparous lactating cows. J. Dairy Res. 75, 457-465.

Meiron, R., Moss, S., Brenner, J., 1997. Bovine leukemia virus-gp51 antigen expression is associated with CD5 and IgM markers on infected lymphocytes. Vet. Immunol. Immunopathol. 59, 113-119.

Mirsky, M.L., Olmstead, C.A., Da, Y., Lewin, H.A., 1996. The prevalence of proviral bovine leukemia virus in peripheral blood mononuclear cells at two subclinical stages of infection. J. Virol. 70, 2178-2183.

Mond, J.J., Brunswick, M., 2003. Proliferative assays for B cell function. Curr. Protoc.
Immunol.(Nov). https://doi.org/10.1002/0471142735.im0310s57. Chapter 3:Unit 3.10 .

Mosmann, T., 1983. Rapid colorimetric assay for cellular growth and survival: application to proliferation and cytotoxicity assays. J. Immunol. Methods 16 (65(1-2)), 55-63.

Okagawa, T., Konnai, S., Nishimori, A., Maekawa, N., Goto, S., Ikebuchi, S., Kohara, J., Suzuki, Y., Yamada, S., Kato, Y., Murata, S., Ohashi, K., 2018. Cooperation of PD-1 and LAG-3 in exhaustion of $\mathrm{CD}^{+}{ }^{+}$and $\mathrm{CD} 8^{+} \mathrm{T}$ cells during bovine leukemia virus infection. Vet. Res. 49, 50.

Orlik, O., Splitter, G.A., 1996. Optimization of lymphocyte proliferation assay for cells with high spontaneous proliferation in vitro: CD4 $+\mathrm{T}$ cell proliferation in bovine leukemia virus infected animals with persistent lymphocytosis. J. Immunol. Methods 15 (199(2)), 159-165.

Polat, M., Ohno, A., Takeshima, S.N., Kim, J., Kikuya, M., Matsumoto, Y., Mingala, C.N., Onuma, M., Aida, Y., 2015. Detection and molecular characterization of bovine leukemia virus in Philippine cattle. Arch. Virol. 160, 285-296.

Pyeon, D., Splitter, G.A., 1998. Interleukin-12 p40 mRNA expression in bovine leukemia virus-infected animals: increase in alymphocytosis but decrease in persistent lymphocytosis. J. Virol. 72, 6917-6921.

Schroder, K., Hertzog, P.J., Ravasi, T., Hume, D.A., 2004. Interferon- $\gamma$ : an overview of signals, mechanisms and functions. J. Leukoc. Biol. 75, 163-189.

Soder, K.J., Holden, L.A., 1999. Lymphocyte proliferation response of lactating dairy cows fed varying concentrations of rumen-protected methionine. J. Dairy Sci. 82 , 1935-1942.

Sordillo, L.M., Hicks, C.R., Pighetti, G.M., 1994. Altered interleukin-2 production by lymphocyte populations from bovine leukemia virus infected cattle. Proc. Soc. Exp. Biol. Med. Sos. Exp. Biol. Med. 207, 268-273.

Souza, F.N., Latorre, A.O., Caniceiro, B.D., Sakai, M., Kieling, K., Blagitz, M.G., Della Libera, A.M.M.O., 2011. Apoptosis of CD5 + cells and lymphocyte proliferation in bovine leukemia virus-infected dairy cows. Arq. Bras. Med. Vet. Zootec. 63, 1124-1130.

Stone, D.M., Hof, A.J., Davis, W.C., 1995. Up-regulation of IL-12 receptor alpha and MHC class II expression on lymphocyte subpopulations from bovine leukemia virus infected lymphocytotic cows. Vet. Immunol. Immunopathol. 48, 65-76.

Trainin, Z., Brenner, J., Meirom, R., Ungar-Waron, H., 1996. Detrimental effect of bovine leukemia virus (BLV) on the immunological state of cattle. Vet. Immunol. Immunopathol. 54, 293-302.

Van den Broeke, A., Ouamouna, M., Beskorwayne, T., Szynal, M., Cleuter, Y., Babiuk, S., Bagnis, C., Martiat, P., Burny, A., Griebel, P., 2010. Cytotoxic responses to BLV tax oncoprotein do not prevent leukemogenesis in sheep. Leuk. Res. 34, 1663-1669.

Vries, E., Lafeber, G.J., Van der Weij, J.P., Van Buijsen, A.C., Leijh, P.C., Cats, A., 1980. Pokeweed-mitogen induced lymphocyte proliferation: the effect of stimulation on mononuclear phagocytic cells. Immunology 40, 177-182.

Yakobson, B., Brenner, J., Ungar-Waron, H., Trainin, Z., 2000. Cellular immune response cytokine expression during the initial stage of bovine leukemia virus (BLV) infection determines the disease progression to persistent lymphocytosis. Comp. Immunol. Microbiol. Infect. Dis. 23, 197-208. 